\title{
E-Learning Strategy Development for Fully Aligned College Curricula
}

\author{
Abdelrahman Abdelazim \\ Advanced Engineering Department, Blackpool and The Fylde College \\ Ashfield Road, Blackpool FY2 0HB \\ E-mail: aab@blackpool.ac.uk \\ Margarita Georgieva* \\ Advanced Engineering Department, Blackpool and The Fylde College \\ Ashfield Road, Blackpool FY2 0HB \\ E-mail:mgeo@blackpool.ac.uk
}

\begin{abstract}
The background of this study is a well-established $21^{\text {st }}$ century trend, leading education institutions towards diversifying their offer with e-learning. While top engineering institutions worldwide have developed e-learning, many others were still focusing on limited traditional offers until the COVID-19 pandemic of 2020 which has brought unprecedented upheaval and drastic change even for small local colleges. The aim of this study is to analyse the dimensions of this change and evaluate the change management processes across engineering departments in local UK colleges that have had to shift their teaching, learning and assessment from face-to-face delivery to an e-environment in the context of the COVID-19 pandemic, and are considering moving onto elearning wherever possible. The initial research for this study has been collected across 77 further education colleges in the North West of the UK that also have a higher education offer and that teach engineering at various levels. Key aspects of the move to e-learning as well as the wider context will be presented, followed by a contextualised literature review where examples of challenges from analysed institutions will be presented in relation to key concepts of change management. Some critical aspects of higher education across colleges are considered along with their challenges in the present COVID-19 context. This will be followed by recommendations. The basis for the recommendations is an extended market and change management analysis available in the appendices to this work. SWOT, Porter's Five Forces as well as stakeholder analyses are complemented by Culture Web and McKinsey's 7S models which have been used to analyse the current state of operations and present strategic positioning of UK colleges with an engineering further and higher education provision in order to identify which of these may need reinforcement and propose recommendations.
\end{abstract}

Keywords: e-learning, higher education, strategy, colleges, engineering education

DOI: $10.7176 / \mathrm{JEP} / 11-36-01$

Publication date: December $31^{\text {st }} 2020$

\section{Backgrounds}

The major consideration in this work is the difference that persists in the UK between local colleges and universities. A number of engineering departments across local UK colleges have both a further (FE, teaching 16 to 19 year olds) and higher education (HE, open to any student 18 and above) offer along with some commercial courses open to professionals or those seeking to reskill, and delivering Welding, Machining, Inspection, Health and Safety, Project Management, Computer Aided Design (CAD) and other technical classes with teaching staff at various academic levels, ranging from $\mathrm{HNC}$ to $\mathrm{PhD}$ qualifications in some rare cases. Some departments across 77 north-western colleges (NW England Directory, 2020) which were part of this study are changing rapidly, drifting towards a university-like environment, with an influx of newly recruited tutors to renew posts that are either available due to increased student intake or retirement of staff. Several colleges have now merged with their university partners, strengthening their competitivity on the market. (Georgieva \& Abdelazim, 2020) However, the move to e-learning courses exclusively delivered online is still slow for colleges (Tomblin, 2019), whether on account of strong academic platforms worldwide or for other reasons found in the managerial leadership strategy of these institutions, which is also true internationally. (Abdalmenem, et al., 2019)

E-learning is a developing phenomenon for both general and subject-specialist topics in engineering. (Morard, et al., 2014) A few HE providers have dedicated e-learning platforms where short courses in engineering are offered to industry professionals or the general public. Some are freely accessible with key certifications available after paid verification processes and others exist on an open learning basis. In this context, technology and virtual reality have gained grounds in the development of state-of-the-art virtual learning environments (VLE). Some are developed in-house while others are off-the-shelf products. Disruptive technologies and ground-breaking innovative teaching, learning and assessment methods with the integration of AI are expected future developments. Colleges across the North West have been aware of these developments for a while. Leadership structures are 
changing, and new managerial teams appear to be working towards catching up with newest developments in education, renewing the offer and planning for the next five years. In some cases, institutions drive a digital transformation agenda. (Tomblin, 2019) With the COVID-19 pandemic, many will move towards a drastically different approach to delivering its programmes to stay viable, including increased digitisation. However, this development had been planned in the long, rather than the short run, and has often been precipitated. Before the pandemic, several wider management forums have discussed the implementation of full e-learning as high on the agenda. (Tomic, et al., 2020) Ideas have been generated in the past decade at institutional level and include proposals for contract changes and redesigned approach to human resource management. (Sharpe, et al., 2006) New strategies may take years to implement, but with the pandemic, what had been a planned transition for years has now taken place within weeks.

Until the pandemic, e-learning has not been an externally imposed strategy. Despite the precipitation and several confusing messages from Ofqual and awarding bodies, this remains the case to-date. As the communication of external stakeholders mostly emphasises, implementing teaching, learning and assessment online currently persists without clear guidelines, and logical incrementalism (Augier \& Teece, 2016) remains the preferred approach. For many colleges, the initial plan included the introduction of a VLEs, training staff, and providing needed support. In a number of institutions however, this has led to additional re-evaluation of programmes and courses for e-learning suitability. Whilst most organisations seem to have bought into this need, the implications of the proposed changes on employees and their reflection on the subject is still largely unknown and is still being analysed, mostly across opinion pieces in media communication.

The present case study is based on arguments gathered for each dimension of current change management models and frameworks along with recommendations for future development and organisation, framed by urgency - new demand for adaptation and changing student needs and industry partners. A large portion of the reflection is based on the need to preserve current partnerships, seek new ones and find methods for sustainable development. Before analysing the actions and change management approach in this context, however, it is crucial to frame it in a theoretical perspective delineated by key literature in the field. The data used for the various analytical models employed has been collected across UK Government websites, professional body and industry reports and white papers, and from publicly available college reports since 2019.

\section{Current Trends in E-Learning Strategy for UK Colleges}

E-learning may be at the heart of education in the future. However, defining it as deliberate or emerging strategy (Johnson, et al., 2017) is difficult. Referred to as "blended learning", in its current state it reflects colleges' strategic leadership, vision and progressivist planning, integrating a logic of incrementalism: face-to-face offer is complemented, then gradually supplemented, by e-learning. Although evidenced successful for many organisations, the strategy to implement and sustain e-learning is as challenging as any other change initiative. Doubt whether e-learning, as delivered by colleges at present, is pure deliberate or emergent strategy (Mintzberg \& Waters, 1985), stems from the fact that they already have some blended/distance learning programmes. Releasing e-learning as a mainstream offer has been precipitated by the pandemic in a new form. Yet, plans for it existed previously, albeit not projected for release at current pace. Nevertheless, the umbrella approach (Mintzberg \& Waters, 1985) is undertaken where both intended changes and obstacles faced are dealt with through change management in a unique combination of force majeure circumstances and new opportunities.

Strategic drift (Johnson, et al., 2017) remains an important part of this reflection. While the learning curve is steep, and a high level of adaptation to novelty at all stages is required, governmental bodies and institutional leadership are confident that the emerging ways of working will benefit all stakeholders and may very well save the business. While "change death" (Johnson, et al., 2017) could occur, subject to internal or external factors, efficiency can thrive. Its associated impacts will include staff and students saving time and adapting to new technologies in an ever-changing world. Nevertheless, political aspects and embedded culture, both internal and external, continue to shape the change process. Among the key points of contention is the preservation of timeand resource-heavy quality and monitoring processes. Others are focused on teaching, learning and assessment proper with decisions that need to be made on vocational skills, practical workshop delivery and examination policies.

Despite the prevalent belief that e-learning is transformational change, clear evidence demonstrates that this process in UK higher education is for now merely a realignment change (Balogun, et al., 2016), whether due to the fact that readiness for transformation is minimal or because it is still too early to tell. COVID-19 driven phenomena are mere realignments of practice, reflected by a "business as usual" strategy with limited changes in planning and timetables, and persistent unknowns. Staff resources have been utilised in a manner similar to the pre-pandemic organisation, disregarding optimisation or cost effectiveness. There is an absence of genuine innovation on the clean slate that the pandemic offers. Most colleges seem to cautiously rely on processes and systems used in the past with the added feature of e-learning or blended approaches as a temporary solution to phenomena that may very well persist. 
The strategic transformation cycle's middle step (Johnson, et al., 2012) consists in waiting for a happy accident, then seizing the opportunity it provides. Here, the happy accident may have occurred but it is unclear if it will be exploited. Some believe that the pandemic, despite its negative impacts, could be the happy accident for the advent of a new way of teaching and learning. The College's risk-averse approach maintains that this may not be a happy accident. However, incremental, well-thought-of steps and consistent mentoring to achieve fast adaptation can lead to a success story. Incremental improvements could lead to sustainable success (Hope Hailey \& Balogun, 2002) and that can be considered the happy accident. For UK colleges offering both FE and HE, the proposed changes in relation to the pandemic are so far based on economic value (E theory). Organisational capability ( $\mathrm{O}$ theory) exists in a lagging, unstructured system that needs strength for the change. (Beer \& Nohria, 2000) New initiatives and team restructuring have taken place. However, developing and retaining teams and students is a priority at this stage.

Meanwhile, the unanticipated outcomes (Balogun, 2006) of the global change that is occurring have been declared goals to utilise and enforce. While a number of teaching teams have upped their communication with good practice emerging with the change, teaching, learning and assessment lockdown research originating in colleges is a double-edged sword. While there is no doubt about the positive impact on some staff members' motivation, encouraging them to adapt new practices and change their norm, the vast majority struggle to see the relevance and rush to declare all early wins as irrelevant to their daily reality. Periodicals such as The Chronicle of Higher Education reflect these sentiments on a global scale. The feeling of detachment has increased as the celebration of early wins is taken as clear indication of the continued ignorance about daily work-related struggles. Middle managers have limited options and while trying to balance managing staff and changes, adapt and declare early wins, mini-success stories in their areas, to maintain their image and provide the executive team with the required narrative. Thus, the rhetoric of "good" performers versus "bad" players persists on front-line staff level as well as in the classification of the Office for National Statistics. This is not sustainable nor leads to long-term wins.

Ambidexterity (O'Reilly \& Tushman, 2011) in large organisations is utilised to a certain extent, reflected in new relationships between stakeholders. All five propositions are readily available to colleges and can be considered even though this is not widely the case at present. With over 70 institutions sharing similar requirements and provisions, and expected to provide similar results, the learning curve and practical best-practice sharing are limited to vertical government-institution communication. We now see some initiatives tested, and whilst considered the best approach for learning about change, the trials are not systematically completed with welldocumented lessons learnt that are shared and institutionalised. Feelings of hesitation and uncertainty prevail. Teams are left wondering about best approaches. A shared learning curve can only be achieved in a stakeholder structure where most players are situated in the same quadrant. A drastic shift in stakeholder structure post-change is necessary.

\section{Market Analysis, Change Models and Frameworks \\ 3.1. Change Models and Frameworks Overview}

With the pandemic, it has become obvious that some aspects of change management across colleges are lacking in strength. The Culture Web and McKinsey's 7S (Johnson, et al., 2017) models are advantageous for an initial study to evaluate whether organisations are ready for change, to consider a holistic view of all the dimensions the change will affect and to pinpoint the major areas of weakness. What these models do not reflect, however, is the quality of the product to be marketed and how this quality will change (or not) as a result of the change. Variations in quality may determine the future of the business. The change may result in higher quality output, but these models do not propose a benchmark for measuring that. It would be beneficent to develop alongside both models a qualify function deployment plan or a strategy based on the balanced scorecard method. However, neither the Cultural Web, nor McKinsey's 7S model clearly propose an integrated approach to quality management of engineering provision in colleges.

Change Kaleidoscope reflection should also be undertaken to re-think and consider restructuring project management processes that will drive a possible change strategy. Arriving at the conclusion that the readiness of the teams and institution is low, Kotter's Change Management theory is utilised to develop a forward-looking strategic ideological direction of the change. In addition, the project management approach to change of Sirkin, Keenan and Jackson (Sirkin, et al., 2005) is utilised for its practical translation. The weakness of the Change Kaleidoscope, similarly to those of the other modules, is that it presents a temporary snapshot of the state of things at a given time. It will therefore have to be redrafted as soon as minor changes are implemented. The main weakness of Kotter's Change Management is that the strategy operates at high managerial level and requires strong and recognisable leadership, which the institution is currently lacking.

While the models help reveal different facets of a case study, the conclusions they provide are limited when used as standalone framework for change. The strength of the models lies in their concurrent, creative use and the addition of other analytical tools. Hence, additional elements used for developing recommendations include Force 
Field Analysis, SWOT, PESTLE and Porter's 5 Forces to examine various market aspects of the change. The various analyses are organised across two sections spanning an initial market research an analysis for the educational products on offer, followed by change management analysis, evaluating the various aspects of the department, its readiness for the change and potential resulting strategy.

\subsection{Market Analysis: Should colleges change?}

Market research and analysis were carried out primarily with the purpose of determining whether the engineering departments should continue with the change to e-learning post-COVID-19 or return to their habitual face-to-face delivery practice as soon as lockdown is eased. We will then look at each of the change models and frameworks and will identify, for each, the areas that present the weakest points for colleges across the North West.

PESTLE analysis (Figure 1) aimed to determine whether the current climate is appropriate for the development of online and blended learning. One of the main conclusions arising from the survey of all the key factors is that engineering departments in colleges are significantly behind other institutions and training providers in this respect. This is particularly true for higher education qualifications. The political and economic climate, accompanied by significant progress in technology for teaching, have given a substantial push to online and blended leaning opportunities with fully online based providers for Higher National Certificates and Diplomas now available and fully backed by Student Finance and Pearson. A number of international institutions offer entire courses with certifications and the opportunity to engage in modular degrees by collecting courses that, when completed, constitute a full degree. Balancing the risks to the business in the long run is crucial at this point as there may be very little choice in the matter. Currently, the quasi totality of educational institutions have transited to some form of online delivery and are planning for this to continue beyond the COVID-19 crisis. This may be followed by an economic crisis and, to a certain extent, Brexit uncertainty in December 2020 will contribute to that. There is no knowing what the impact of this atmosphere will have on part-time students who are at work in industry, and who may prefer remote delivery with opportunities to validate practice at the workplace. This is increasingly the case with higher and degree apprenticeships as well as for some further education apprenticeships.

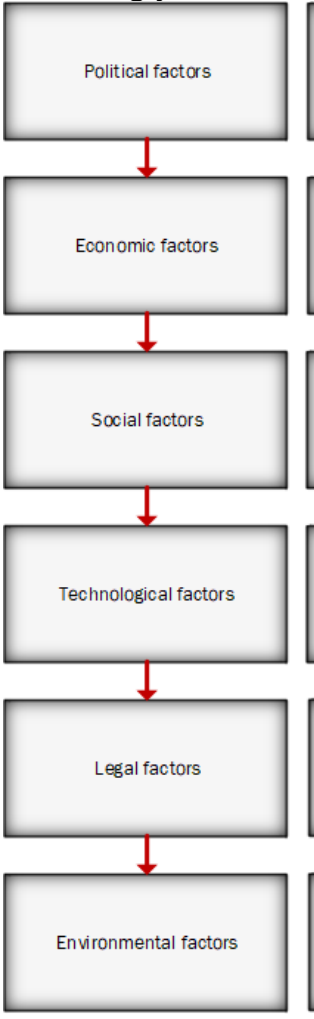

Currently, there is a sentiment of uncertainty about the possible Government action plans for the post-COVID-19 future, which affects students coming from countries such as China and other countries outside the European Union. The UK is set to exit the Euro zone in December 2020, bringing additional uncertainty regarding European students. Many students may choose to stay closer to home and may not come back to their studies, or in the event of coming back may be held under quarantine. Political parties are engaged in a struggle with foreseeable repercussions on higher and further education funding, along with certain areas being priviledged. Engineering may be in a privileged position to boost the economy.

The economy has taken a shock due to the global pandemic, but many opportunities have been created. A number of online businesses are thriving, especially with the new opportunities for short courses and certifications in Risk Management, Crisis Management and others. It is an advantageous specilly with the new opport tele across many of its aspects, including family and work life.

Many employees have been furloughed and companies are looking for opportunities to upskill them. Many students may have lost jobs, impacting on their financial situation. A significant number of people in the service industry along with restaurant, bar and hotel owners specifically in Blackpool and the environs are seeing a dramatic decrease in their revenue. The lockdown is taking a toll in terms of social distancing, affecting mental health and wellbeing. Simultaneously, people's online presence is significantly higher now as they reach out through others online, driving demand for technological progress and directly impacting technological factors.

The release of 5G, Artificial Intelligence development and automation / robotics across the Engineering industry and bioengineering are an exceptional combination of factors, driving dramatic and unprecedented change that will propel technology to new heights. A number of education service providers already have online courses in these areas. There also is a significant online offer on demand along with free courses across rapidly developing e-learning platforms. Social media are booming, allowing for educational advertising to flourish.

The most notable recent development is The Health Protection (Coronavirus) Regulations 2020 and The Coronavirus Act of 2020. These ensure social distancing is in place and also define various measures for combating the disease. They impact on everyday life as well as operations on-site with a number of companies now closed and operating online. Further legislation currently being debated is on diversity and equality, and sustainability. Each of these topics can be looked at in the light of potential elearning offer, eg improving sustainability and equality siven equal access to technology and internet that can be made possible with technological factors in force.

Legal factors will soon be impacting environmental factors with various sustainability aspects currently being debated in Parliament. The lockdown has revealed a number of environmental concerns, including a resurgence of issues, which may be subject to Engineering solutions in the long-run, These include topics in agronomy (farming), equal access to services and others, constituting possible venues for research and scholarship as well as Inked educational offer. Sustainability issues in personal and public finances as well as the financial health of companies in the current economic situation are also subject of concern within the business environment.

\section{Figure 1 PESTLE Analysi}

Porter's 5 Forces analysis (Figure 2) examines the competitors and players on the market to determine whether the current positioning is right. The market presently has a very wide offer, ranging across degrees, apprenticeships, longer and short courses, and certifications, hence diversification is key. A number of competitors have already seized the opportunity and are established providers. However, there are very few colleges who are engaging in online and blended learning and herein lies the unique opportunity for further education colleges with a higher education offer. They can perform better locally and attain a regional and national standing in the field of technical education, specifically in engineering after the fashion of European institutes of technology. Good 
opportunities for new player entry exist at present due to both economic and social factors linked to the COVID19 pandemic, and any venture linked to the provision of engineering education may obtain support from a range of sources, including political and economic players. High diversification seems necessary as well as a strong identity, accompanied by recognisable branding and accreditations, both national and international.

\section{Buyer Power}

Varies greatly depending on whether students are relying on loans or are being financed by employers. Overall, students want to choose the best qualifications as well as the most relevant ones for the jobs there are doing. They have significant influence over the market.

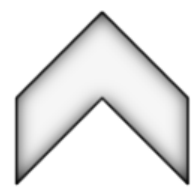

\section{Threat of New Entry}

There is continuous new entry of smaller or larger players and offer is diversified and continually evolving. The focus is on ease of access and consumer preference based on accessibility and user-friendliness of e-learning platforms as well as prestige of the provider

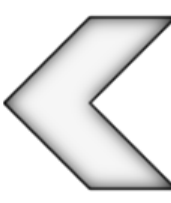

Competitive rivalry in e-learning and online education focuses on constant tension and balance between the offer of universities and private organisations.

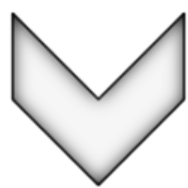

Supplier Power

Varies based on provider image but also high ability to contro the qualifications on offer, effectively regulating the market. For some providers, there is an interdependence between need on the customer and provision capacity of the supplier with many instances where both work together to develop innovative products and services.

\section{Threat of Substitution}

Can be very high when disruptive technologies or software come into play. New emerging trends see industry players enter the market with educational material aimed at professionals. Various forms of on-site training for engineers are also available, threatening traditional qualifications.

Figure 2 Porter's 5 Forces Analysis
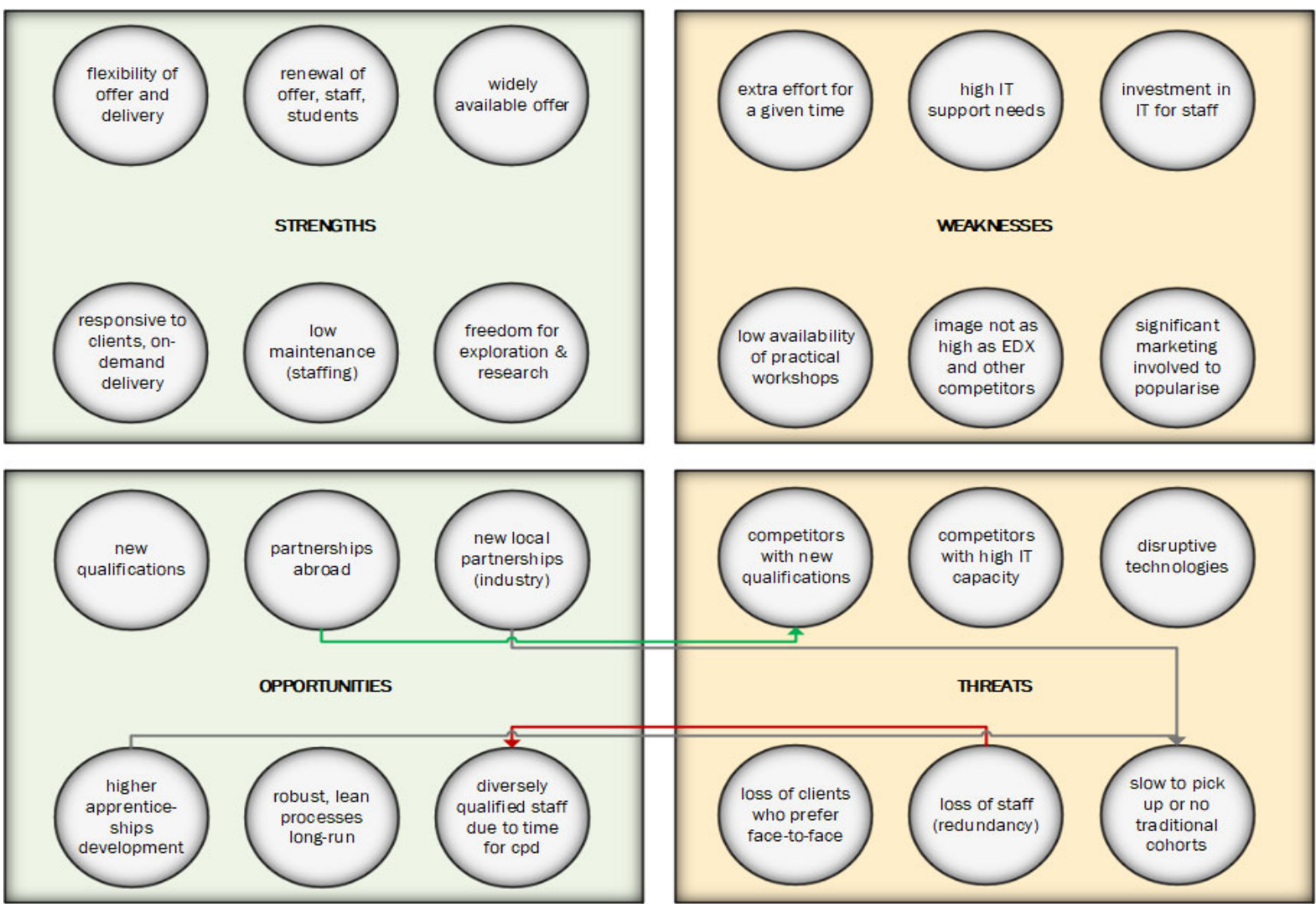

Figure 3 SWOT Analysis 
SWOT analysis (Figure 3) aims to develop an understanding of the effects and impacts of the change in order decide whether it is worthwhile to deploy online and blended learning across engineering qualifications offered by colleges. Overall, it appears that most weaknesses can be overcome with the strengths being clearly more advantageous in terms of business in the long run. However, some of the threats are non-negligible, especially those linked to other, stronger players on the market and direct competitors with better technologies. It becomes clear that college engineering departments must develop an offer with additional strengths, such as, lean management approaches, agile teams and delivery processes, and a careful cyclical project management approach to ensure high quality is met. Key players in the stakeholder analysis (Figure 4) can be of help here, e.g. the IET and partner universities as well as any future industry partners nationally and internationally which engineering departments must continue must seek in order to mitigate the threats.

CURRENT (PRE-CHANGE) POSITIONING

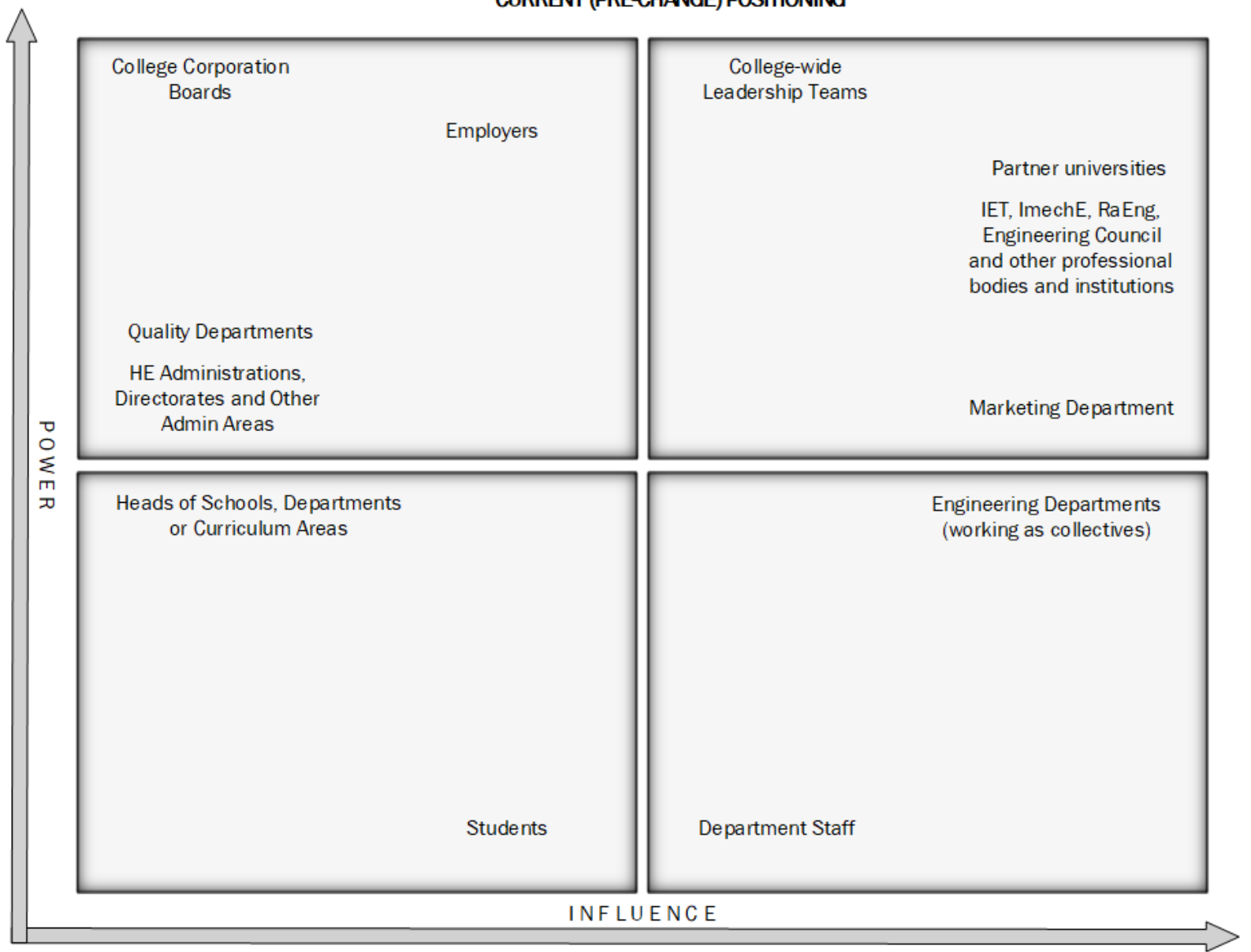

Figure 4 Current (pre-change) stakeholder analysis does not fully empower those who deliver core business

\subsection{Change Models Analysis: Are colleges ready to change?}

Having established that it is advisable for the engineering departments to continue with an online and blended learning offer, and to engage in change management relative to these, further analysis has been carried out in order to determine how ready the people, systems and their users are for such a change, and in the case where this is found to be lacking, to engage in a healthy plan for successfully progressing to a new transformation phase.

The Culture Web analysis (Figure 5) has helped reveal certain strengths and positives as well as certain disadvantages of the current paradigm. Overall, it appears that strategic partnerships and recent developments are leading many departments towards a positive change, but not fast enough, and that while quality aspects and other operational hurdles can be overcome with occurring change, there is a substantial lack of attention as to the stories that these departments tell about themselves. This is true for the beliefs key staff entertain about themselves, their abilities, purpose and future as well as the stories that are projected outwards and told to potential clients about their mission and vision. This indicates an urgent need to work alongside Marketing Departments to realign communication, to address and realign the official institutional and departmental identity narratives. This will have to go hand-in-hand with the image engineering should have nationally and internationally through initiatives such as "This is Engineering". The change that e-learning will bring will in turn bring positive institutional change with a shift of vertical power structures and hierarchies to more flexible horizontal ones. It also appears that the change 
may have a positive effect on quality processes, bringing about simplifications and a newer, leaner approached to operations. This shows not only readiness to change, but also a necessity.

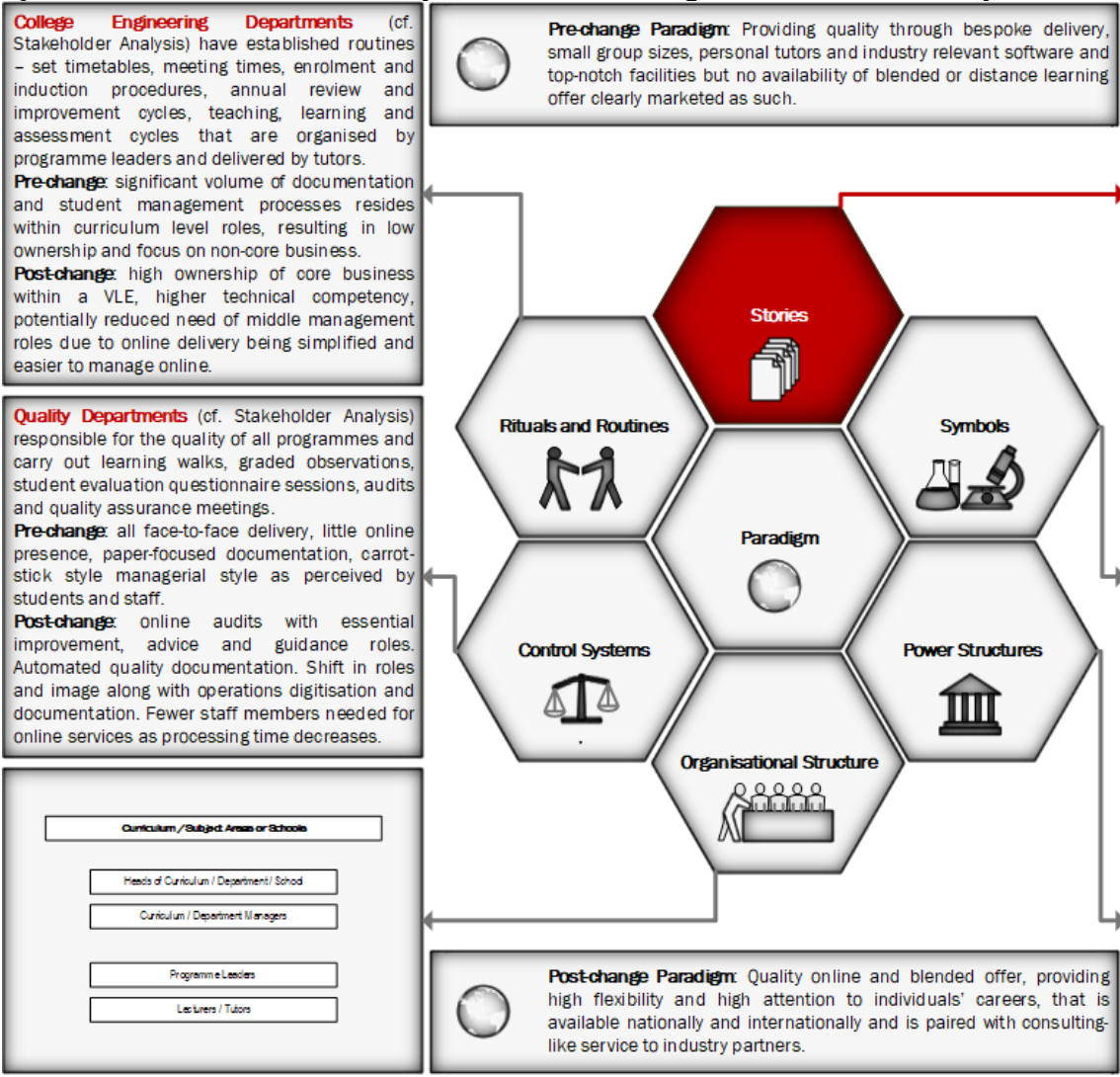

Marketing Departiont Stakenolder Analysis) partially drives the narrative about the engineening offers of colleges through the punclication of pre approved stories of successes pur ha is a lack of student success stories. Advantage consistent across colleges

Disadvantage low relevance to online offer University Partners (c. Stakeholder Analysis) partially drives the narrative about college-level departments through validation documentat which finds itself on documents and website. Advantage: relevant, high academic standard, excellent documentation Disadvantage separate validation processes for online and blended learning offer

Marketing Departments (cf. Stakeholder Analysis) drives the visual representation of colleges in terms of graphics schemes and institutionally approved messages as well as pictographic material. This affects engineering departments in that there has to be a certain level of conformity to the official symbolism.

Prechange: unap pealing marketing schemes and use of generic, rather than bespoke symbols and imagery. Gaps in understanding key messages of engineering, impacting storytelling

Postchange new staff understands younger audiences and can initiate a gradual change in institutional symbols that are more in line with a younger vision, i.e. "This is Engineering"

College Corporation Boards and Collegewide Leadership Teams (cf. Stakeholder Analysis) hold formal power over all structures and staff in a vertical, hierarchical structure. Change is usually driven by these stakeholders.

Advantage only a few key players need to be convinced in order for change to be initiated. The buy-in of only a few is strictly necessary.

Disadvantage the delineation of corporate responsibility and authority according to power titles and status stifles individul frectom innovations on a personal level, and change is likely to meet with resistance on a wider scale.

Figure 5 Culture Web analysis

McKinsey's 7S model (Figure 6) reveals that the weakest points at present are the systems and by extension their organisation. However, the change to e-learning will necessitate new systems, which will have to focus on greater simplicity, facilitating user experience. Student-orientedness will have to leave the classroom to spread across all areas of activity. The realisation that a student-oriented service is not the prerogative of teaching staff will have to reach the confines of administration, IT and estates departments until the practice is generalised as an institutional strategy. From a systems perspective, agile and lean methodologies will realign engineering departments with industry practices where lean is the norm, bringing more uniformity and consistency in quality overall. Team-based learning, productivity tools (Liekis, 2020) and teaching teams should be the focal points, leading the lean processes. The systems perspective to e-learning strategy can be a more unified approach to connecting learning management systems to users in team-based learning environments. Comparatively, examining current and future positioning based on the change from face-to-face to online delivery, the change will have a favourable impact on organisations as a whole with the establishment of new relationships between key elements of the organisation. For example, where previously were no immediate correlations between organisational strategy, key systems and department structures, the change will fully align them as key personnel will operate systems, strategically driven to grow and improve the e-learning offer. Similarly, greater consistency between style, strategy and systems can be achieved. 


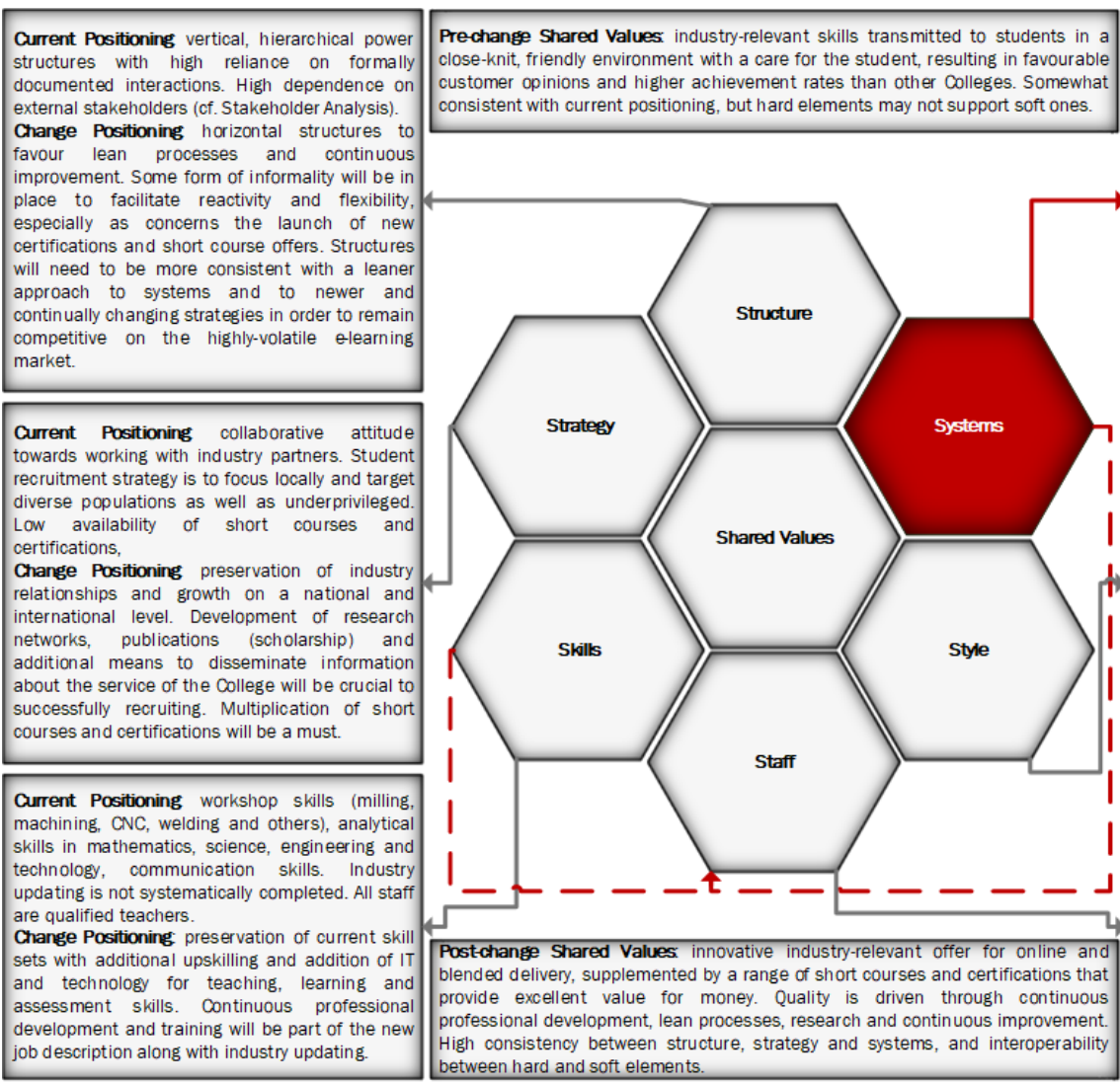

Current Positioning: rigidity of vertical hierarchies reduces reactivity \& increases waiting time for curriculum review. Release of new degrees \& revision of existing qualifications is slow \& labourintensive due to complex processes, bottlenecks and rework. Competitors on the e-learning market are fast and reactive. Rather than facilitating flexibility, the systems in place hinder rapid progress. Teams are heavily dependent on systems in place \& reluctant to embrace novelty. Change Positioning accept simplification of processes and elimination of wastes based on lean continuous process improvement. Complete overhaul of systems, starting with VLE (ongoing), moving to student management systems to combine systems in one performant whole,

Current Positioning there has been a change in eadership on Curriculum Area level, dating back to August 2019, and a clear leadership style is still being defined. Perceptions tend towards a laissez-faire leadership for certain departments and more authoritarian leadership for others. There may be a lack of consistent approach to leadership style in the future. There may be instability as strategy is defined.

instability as strategy is defined. Change Postioning Growh in the area of online degrees and e-learning may lead to progressive detachment of departments and development of other (different) curriculum areas with potential eed to rethin leadership positions. Historically, growing departments underwent similar change.

Current Positioning on the one hand, a team that is growing old and is in need of renewal. A few highly skilled members with a clear divide between technology-savwy and technologyresistant individuals who struggle to embrace change.

Change Positioning High diversity (ongoing), highly skilled (ongoing) and technology-savy, collaborative and positive individuals. There is a need to clearly define tasks and expectations to align them to requirements of accreditation bodies and to new client needs for e-learning. job description along with industry updating. There may be redundancies.

Figure 6 McKinsey 7S Model

There is a complex array of stakeholders, some of which are embracing and driving the change. Overall, there seems to be an awareness of the need for the change and positive buy-in for future change in the same direction,

One part of the staff is ready for the change and aware of its necessity, embracing the change and driving it. Another part is resistant to the change and lacks in autonomy, resulting in a need for training and a certain level of negativity across professionals, reflected in media communication on teaching staff feeling "out of depth" (The Guardian, 2020). There are some proposals for new course design, which shows partial readiness and willingness to innovate if freedom is given.

Engineering departments are usually financially stable with some market threats due to the political and economic situation - context of ongoing pandemic and Brexit. Capacity for change is high as this is in the nature of the field and is a part of the educational profile of all engineers.

Low capability and competence at managing change as many departments are managed either by engineers or ed ucators, or dual special ists, rather than managers with relevant management experience and qualifications. Significant change has been experienced in the past and individuals may view this negatively. There is little expertise in change management as well as low change culture overall.

Figure 7 Change Kaleidoscope Analysis

The Change Kaleidoscope (Figure 7) presents a very balanced view of engineering departments overall with some problematic areas, specifically in terms of readiness for change and resistance. The readiness for change is determined by teams, systems and processes but the factor in highest need of attention at present is the people dimension as will be discussed in the next section where the frameworks for the change will be presented. The
The change is driven by a force majeure circumstance and the time for change is extremely short. Results are expected rapidly. However, the change has been "in the air" for a while with new technologies making their way into teaching.
Entire colleges are affected by the change, but some areas are more affected than others, i.e. vocational courses that require practical work and workshop delivery. Transformation is required and realignment is necessary.
In development, increasingly diverse staff. There are new subcultures across teams and colleges. However, there is a divide between staff who identify more with their engineering profession and those who identify with what college used to be in the pas and with their educator profiles. Significant work on dual professionalisms is needed.
Key skills and staff, as well as teaching learning and assessment processes are essential. Some documentation and processes are not and their removal will have a positive impact on the department. 
analysis of change aspects relative to McKinsey's 7S model (Figure 8) shows that a number of aspects do not find themselves reflected into others. For example, for e-learning to bring successful change, shared values (i.e. digitisation) should find themselves reflected in institutional strategy as well as across its management and teaching styles, across its structures, and should be supported by staff, backed up by skills. It is clear that the aspect that is the least reflected across all colleges part of this study is the very structures of their departments. Other aspects in need of attention are the strategy and systems. Any change and future positioning to be considered should aim to adopt a consistent approach to reflecting each $7 \mathrm{~S}$ aspect within the whole with little to no gaps throughout. The current mismatch indicates that a change is necessary.

Based on the analysis of the Change Kaleidoscope, four design choices are considered. (Figure 9) The design choices matrix is based on a score between 0 to 10 where 10 is the highest level of potential for success based on the factors considered across the Culture Web and the 7S analyses. Two curriculum design choices in particular present themselves as the best options. In both cases, it is important for the department to continue with the current offer and develop in parallel either an e-learning offer based on the current offer or an offer that is additionally diversified into a range of short courses and certifications. In order not to disperse staff effort into too wide a scope initially, these short courses and certifications can be derived from existing offer, and can be offered on a modular approach where a degree is released both as degree (module or course) packages and as a series of short courses with a completion certificate, leading to a scaffolded delivery approach.

\begin{tabular}{|c|c|c|c|c|c|c|c|}
\hline Current Positioning & Shared Values & Strategy & Structure & Systems & Style & Staff & Skills \\
\hline Shared Values & & $x$ & $x$ & $\checkmark$ & $x$ & $\checkmark$ & $\checkmark$ \\
\hline Strategy & $x$ & & $x$ & $x$ & $x$ & $\checkmark$ & $\checkmark$ \\
\hline Struoture & $x$ & $x$ & & $x$ & $x$ & $x$ & $x$ \\
\hline Systems & $\checkmark$ & $x$ & $x$ & & $\checkmark$ & $\checkmark$ & $x$ \\
\hline Style & $x$ & $x$ & $x$ & $\checkmark$ & & $\checkmark$ & $\checkmark$ \\
\hline Staff & $\checkmark$ & $\checkmark$ & $x$ & $\checkmark$ & $\checkmark$ & & $\checkmark$ \\
\hline Skills & $\checkmark$ & $\checkmark$ & $x$ & $x$ & $\checkmark$ & $\checkmark$ & \\
\hline Future Positioning & Shared Values & Strategy & Structure & Systems & Style & Staff & Skills \\
\hline Shared Values & & $\checkmark$ & $\checkmark$ & $\checkmark$ & $\checkmark$ & $\checkmark$ & $\checkmark$ \\
\hline Strategy & $\checkmark$ & & $\checkmark$ & $\checkmark$ & $\checkmark$ & $\checkmark$ & $\checkmark$ \\
\hline Structure & $\checkmark$ & $\checkmark$ & & $\checkmark$ & $\checkmark$ & $\checkmark$ & $\checkmark$ \\
\hline Systems & $\checkmark$ & $\checkmark$ & $\checkmark$ & & $\checkmark$ & $\checkmark$ & $\checkmark$ \\
\hline Style & $\checkmark$ & $\checkmark$ & $\checkmark$ & $\checkmark$ & & $\checkmark$ & $\checkmark$ \\
\hline Staff & $\checkmark$ & $\checkmark$ & $\checkmark$ & $\checkmark$ & $\checkmark$ & & $\checkmark$ \\
\hline Skills & $\checkmark$ & $\checkmark$ & $\checkmark$ & $\checkmark$ & $\checkmark$ & $\checkmark$ & \\
\hline
\end{tabular}

Figure 8 Analysis derived from McKinsey's 7S model and the reflection from the Change Kaleidoscope 


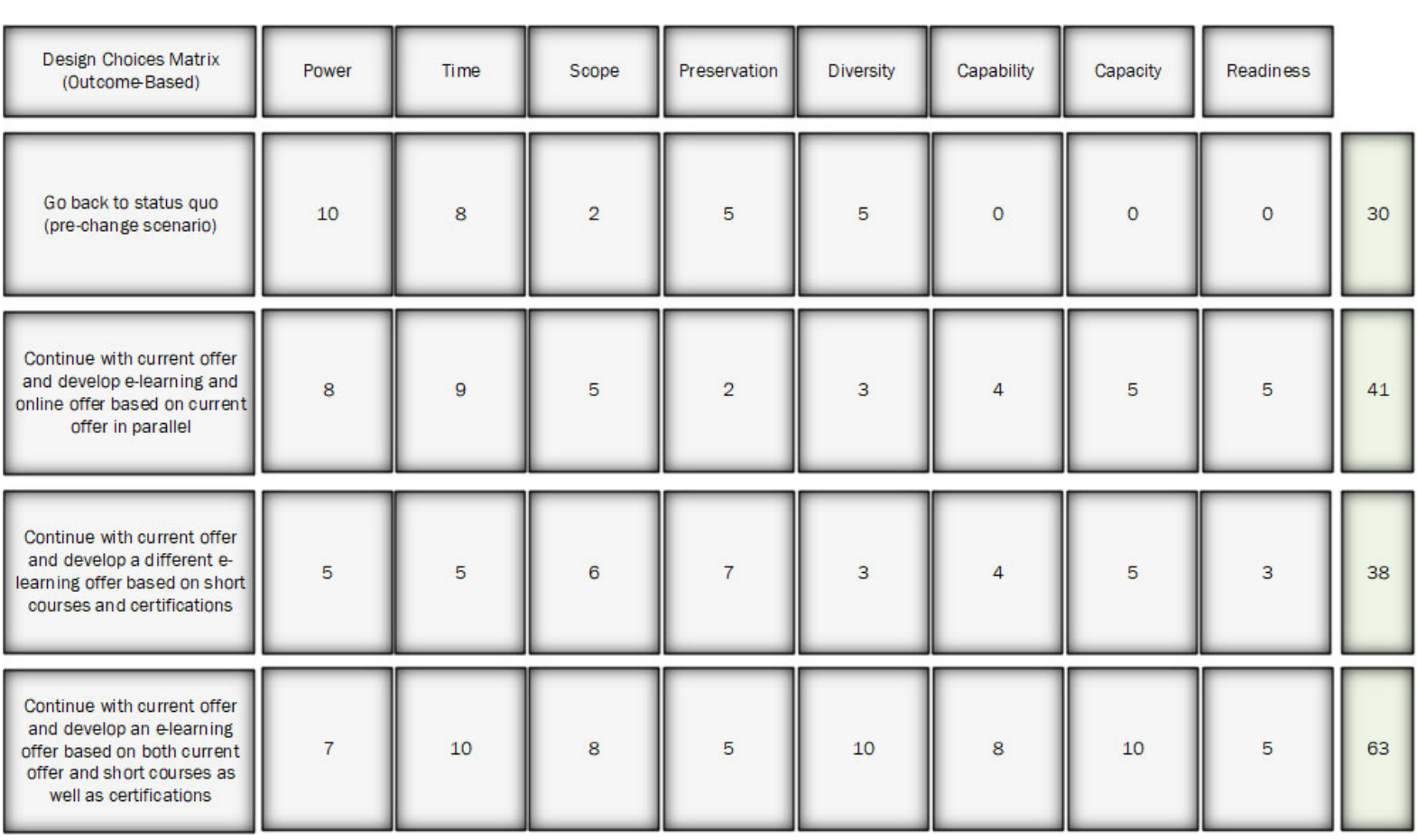

Figure 9 Design choices resulting from the analysis of the Change Kaleidoscope

As all analyses reveal aspects that present different risks to the change project, a Force Field analysis (Figure 10) has been developed, aiming to outline the principal forces for change as well as its main threats, which are broadly distributed over the institution's systems, structure and readiness for change. An interesting aspect is revealed here which shows that while the readiness is not there yet, among the principal strengths currently are the style (in terms of teaching, learning and assessment which are highly individualised and personalised to student profiles), the staff (specifically in terms of their specialist fields and high qualifications) and the associated skills that can be developed through training. Reflected in this is that the e-learning initiative represents a sustainable, progressivist, competitive future for the organisation, a fact agreed by even the most resistant staff. Change happens and is not systematically the result of top-down directives (Tsoukas \& Chia, 2002) Resistance may be fuelled by the attempt of top management to catch up, rather than by the change itself. And as top management is not directly participating in the change, nor has it contributed to mini-successes to-date, they are unable to see the main reasons and forces behind them. A good example can be an engineering department that has adapted and succeed in transforming its offer flexibly with a strong e-learning element that has sufficient agility to be delivered in multiple forms. This is not an overnight success but the result of a long process focused on empowering and ring-fencing a team involved and creating an environment that embraces change. This is where the forces for change become a necessary focus of any change planning. 


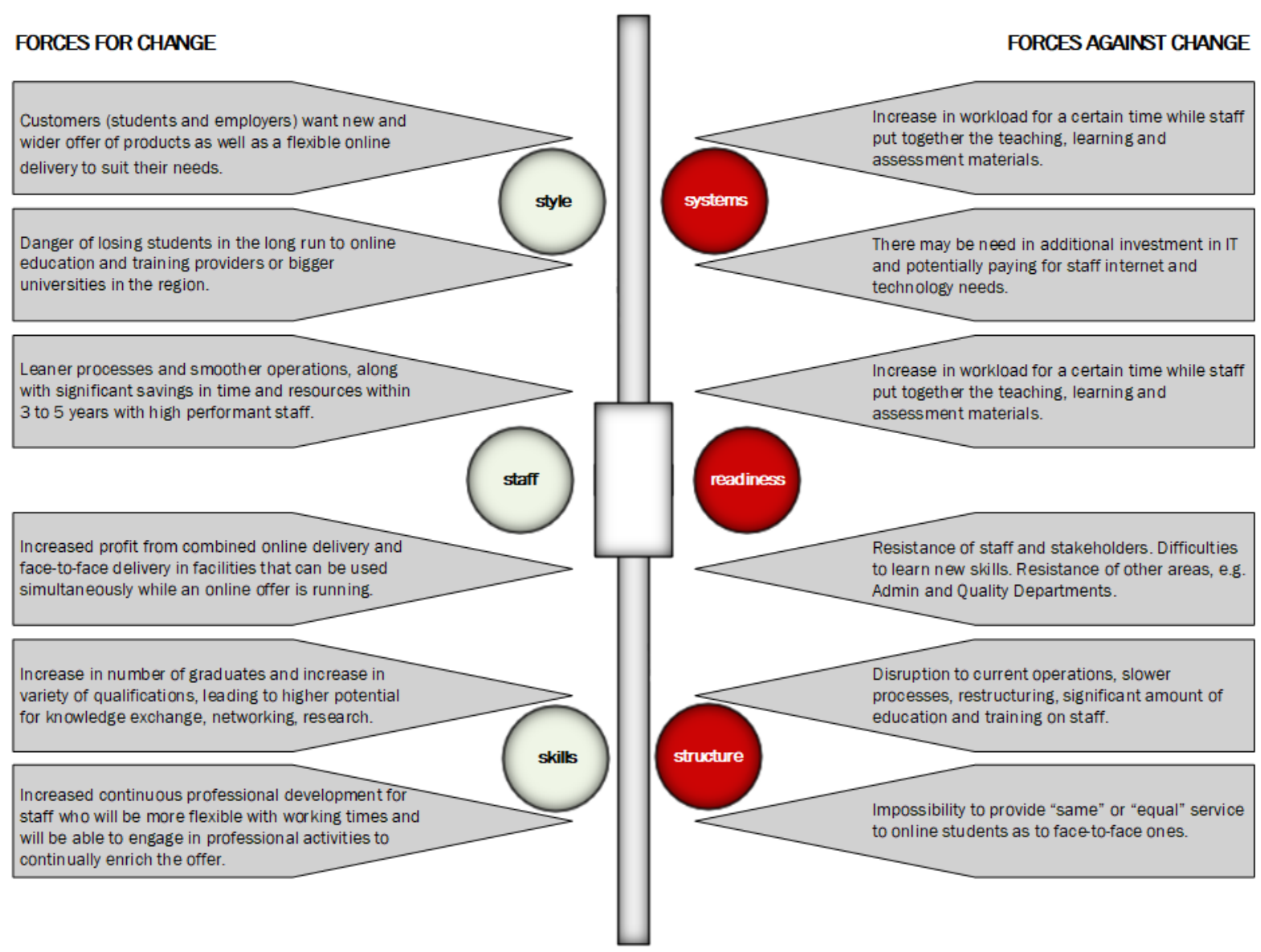

Figure 10 Force Field Analysis

\subsection{Change Strategy Analysis: How should colleges change?}

In order to establish to what extent the forces against the change are in disfavour of the change, an integrated DICE analysis (Figure 11) was performed with the aim to steer positive change, rather than stagnation as in the current atmosphere of uncertainty. A total DICE score of 19 demonstrates that the impact of a low buy-in from teams and lack of readiness along with appropriately organised and managed systems will be detrimental to any change initiated from the current paradigm position. However, as we have seen above, the change is inevitable and it is already controlling the operations, with a negative impact on people and systems. Most of the processes and operations on department level are in transformation, yet are accompanied by old processes, which seems set to continue in the foreseeable future. Engaging in some form of pre-change management will prepare institutions and departments for the move to full e-learning. It seems prudent to plan a series of modifications and readjustments to the status quo prior to engaging in the transformation to e-learning. 

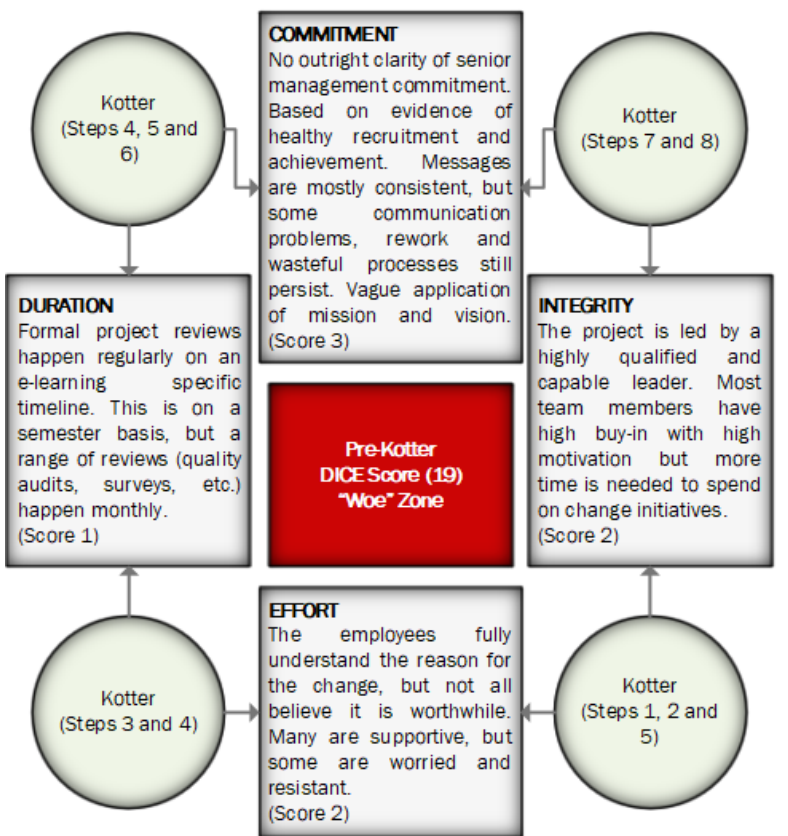

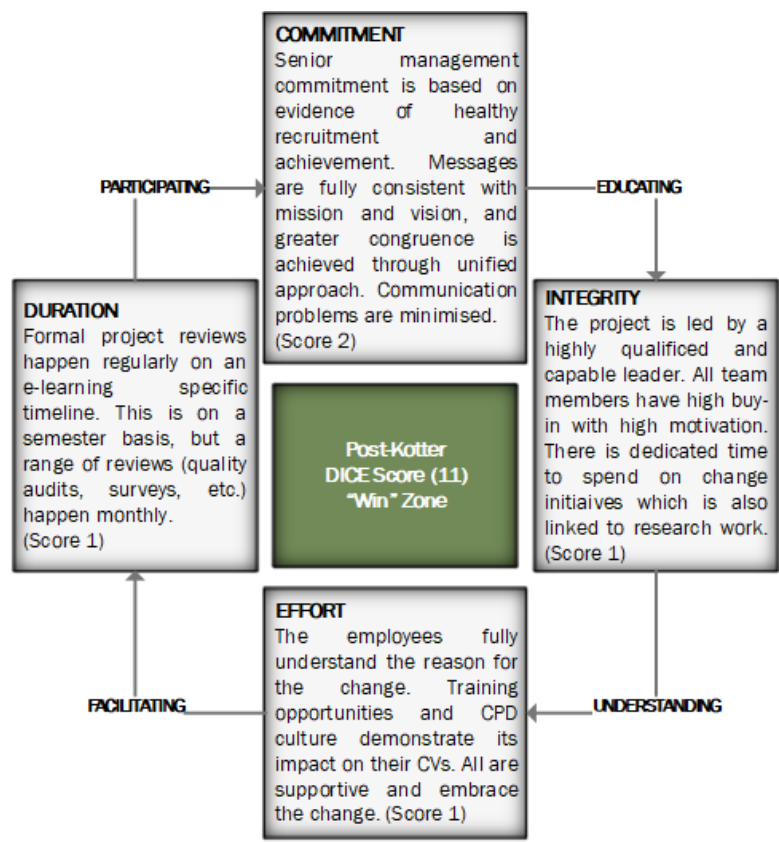

Figure 11 DICE Analysis integrating Kotter's Change Management

It is hypothesised that Kotter's approach, if adopted, will impact the DICE score and will realign the planned changes with projects in the "win" range. The success of this approach can be tentatively monitored through the DICE Framework (Sirkin, et al., 2005). The initial DICE score in the "woe" range portends significant problems without appropriate change management and an action plan in place. This confirms some of the concerns highlighted by the Force Field analysis (Figure 10).

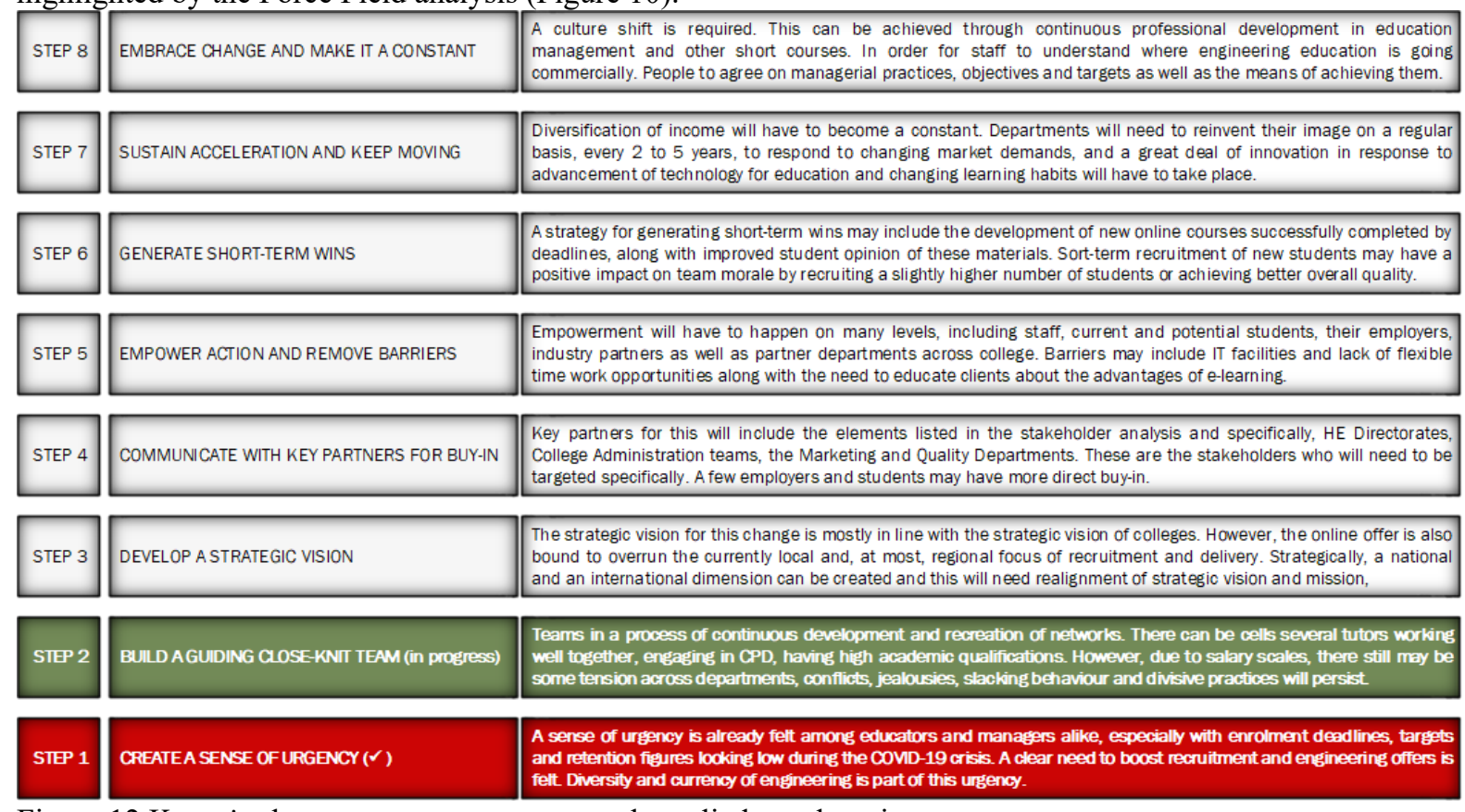

Figure 12 Kotter's change management approach applied to e-learning

The pre-change management effort should be focused on two frameworks where the ideological dimension is based on Kotter's Change Management theory (Figure 12) and will aim to leverage resistance and change. Its step-by-step approach is combined with a concrete phased action plan for change that combines impactful communication with servant leadership (Lowder, 2009) to help teams understand the change, educate them in the new norm, facilitate their access to technologies and knowledge exchange, and enhancing their participation in institutional governance, actively driving its mission and vision, which in turn brings a greater understanding of the need for change and acceptance of that need. This should be accompanied by a robust quality process that is outlined in a four-phased approach to developing quality as the change unfolds.

The four basic theories explaining change processes in organisations (Van de Ven \& Poole, 1995) only partially reveal key aspects of e-learning driven change management in colleges. Time duration is fluid. Ultimate 
goals include both short- and long-term goals that have been planned but whose organisational impacts have not been clearly analysed. Departments have been going with the flow, observing, evaluating, and adopting measures as they appear relevant. There have been no clear deadlines or set timeframes. In many aspects this agility is driven through political aspects of the pandemic management. It could strengthen change sustainability, but it also requires strong management, the ability to accept risk and deal with failure. (White, 2008) Short and medium-term financial impacts are easy to evaluate, but a culture change is still to come at front-line workforce level across the organisation. Another dimension to duration is the lifecycle of the change, the credibility and interference of ground-breaking technology and new players on the market. This is likewise linked to evaluating aspects of change development (Van de Ven \& Poole, 1995), which here are better defined as valuation. There is common agreement between all organisational actors that the dialectic element is must-have for key successes. Yet, middle management are left struggling with resistance from employees unable to cope with change. The view in recent literature is that this can be a powerful tool to reflect useful process feedback, but the challenges can break and kill the momentum. Resistance is seen as the result of high demand which is combined with the additional element of middle managers and their teams having to cope with the change, at the same time "running business as usual" and dealing with pre-change routine processes and tasks as well as post-change processes and tasks, a combination of work and rework that may be detrimental to any change process and results in high initial DICE score. For this reason, it is important to plan a way of leveraging change and the corresponding resistance to it. (Figure 13)

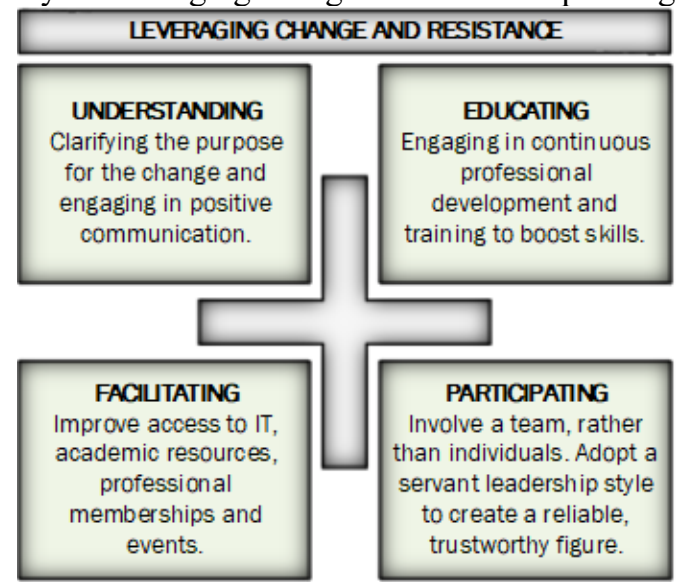

Figure 13 Supporting change will consider ways of leveraging change and resistance to change

Understanding the change is a factor for Step 3 and 4 (Figure 12) where the buy-in of the team is sought and strategic vision is communicated. However, it is also highly relevant for key stakeholders in upper and middle management and external stakeholders with high decision-making power and influence whose understanding of the reality on the group is vital for the shift to e-learning to operate. Understanding of how processes and tasks are perceived and what their impact is on daily operations is crucial to avoiding rework, wastage of resources and recurrence of errors.

Educating the teams for the change will occurs through all steps of the process and this includes a continual education in the methods and tools of the change, as well as continuous education in terms of professional development, boosting core and transferrable skills. The process of educating is connected on many levels with both facilitating access to technology, information, professional development opportunities and other strategic resources and to participating in the decision-making process.

Facilitating access to resources is currently seen as the bulk of the change management budget. It will involve significant investment in electronic resources, hardware and software, databases, professional memberships, elearning trainings and other opportunities for staff, including webinars, conferences, and budgets for continuous upskilling, where necessary for obtaining higher qualifications (degrees).

Participating is linked to a more communal approach to the change management. It will empower those driving the change and will place a certain amount of accountability in their hands, thereby transferring the ownership of the change project to them. The intention is to create an atmosphere where the actors of change establish a connection with the change on a deeper level and identify it as having an intrinsic origin, rather than an extrinsic requirement. Deeper links with the change philosophy are at the core of innovation and engagement that drive further change and favour direct participation of change actors in the decision-making processes.

The highest step in the process which is expressed in embracing constant change will only arrive after sustained transactional communication that connects each step of the process with a corresponding action of understanding the needs and perspectives of all stakeholders, educating those who make the change into its intricacies and stages, facilitating access for key stakeholders to resources that drive their participation into the decision-making process itself to continue driving change as a sustainable, cyclical process. (Tanno \& Banner, 2018) Relevant in this case are the methods of Sergio Marchionne (Johnson, et al., 2017) and the classical approach 
to outstanding leadership that combines strong adaptive leadership centred on leading by example, coupled by listening and empowering everyone in the organisation. Connected to this is a dimension of continuous improvement (based on lean methodologies) which will have to be part of this change and will focus, in parallel, on the processes and systems at operational level, while Kotter's approaches will focus on teams and people from a leadership perspective.

Stakeholder analysis pre-change (Figure 4) reveals a clear cut division in power across job function and managerial standing. This stakeholder structure is partly the reason for the high resistance to change. The most important players in the organisation (clients and those who provide the service, their tutors) find themselves the least empowered and in a bubble that isolates them from decision-making processes. Stakeholder analysis postchange (Figure 14) reveals a very different picture. A redistribution of power is obvious where clients have more impact and significantly higher power. Administration services have an impact on delivery and quality of service, but the decision-making power in terms of content, availability of resources and choice of teaching, learning and assessment now resides in the hands of a teaching and learning collective.

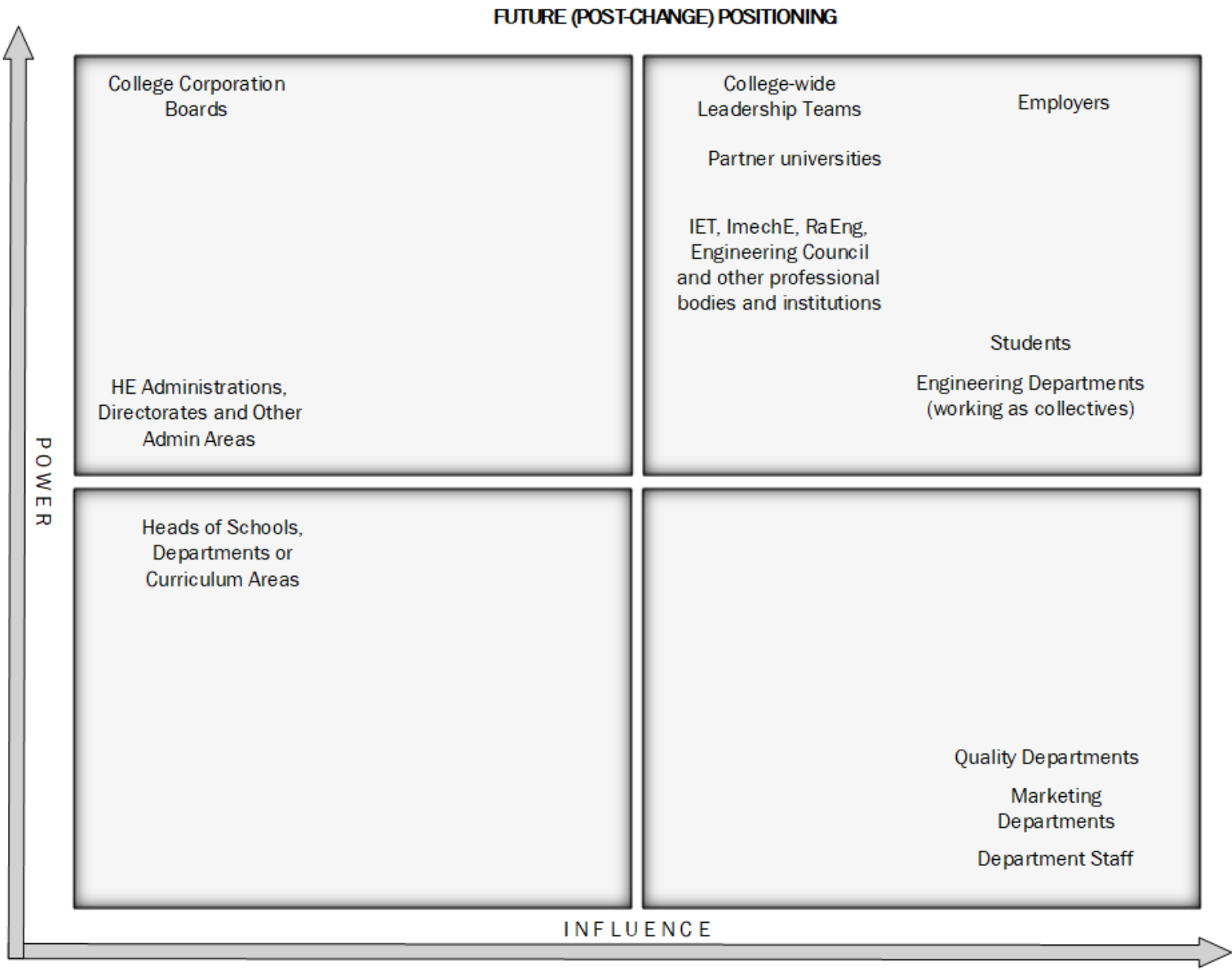

Figure 14 Stakeholder analysis post-change

\section{Future Developments}

Colleges should consider the three isomorphic processes (corrective, mimetic and normative) for their engineering departments. (DiMaggio \& Powell, 1983) In most change processes, simple adaptations will lead to unpredictable results despite the possibility of initial gains. Technology and information widely available to most customers add another layer of complexity for e-learning. Potential students can compare providers and their offer. The UK Government has stressed that all providers should present their offer in a comparable way with emphasis on clarity to students and the quality of the offer. This places additional weight on e-learning validity and quality. Official comparison matrices such as ranking, faculty profiles and credibility are used to compare offers. Focus on their comparative advantage and current paradigm of working with industry partners, focusing on individual's success, should be moulded with the change. The main selling point for colleges currently is small class sizes and investment in state-of-the-art facilities, which have a limited impact on the e-learning market. Therefore, an element of uniqueness across HE modules should be considered, for example, uniqueness in bespoke e-support and an affordable education driving social change. All of these aspects can be reflected in a holistic approach to 
quality. (Figure 15)

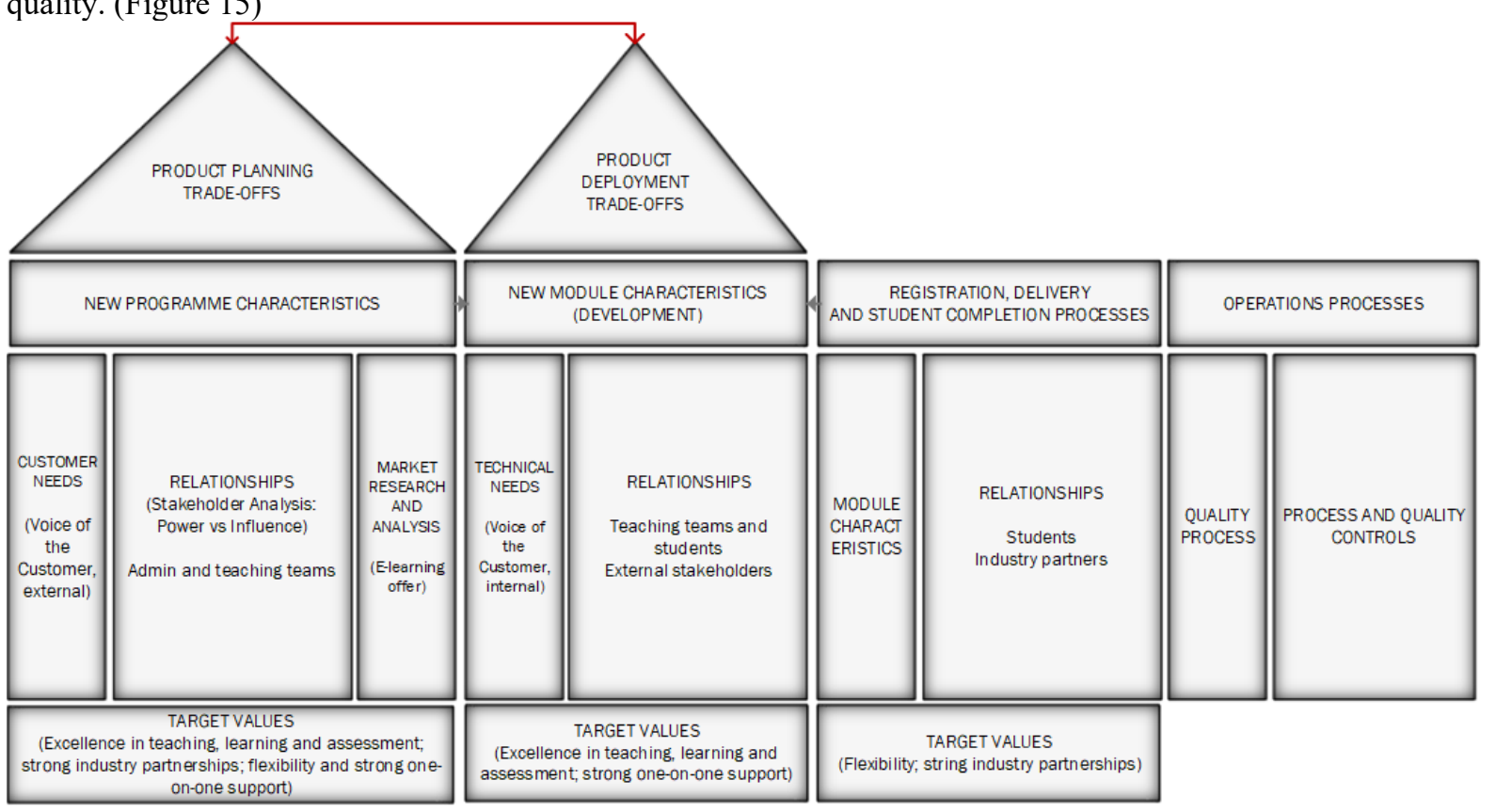

Figure 15 House of quality for e-learning provision in engineering departments across colleges in the UK

The path of change discussed should certainly evolve to match external and internal environment requirements. Even though the starting point has shifted dramatically from the initial plan, lasting and sustainable change is achievable through the style, target levers and roles adopted by change actors, rather than middle managers. In the long run, the highest chance of success lies in the majority driving a continual change cycle. McKinsey's 7S analysis (Figure 6) contains an initial optimistic indication that the proposed change with the currents skills and ability is possible. Staff with transferable skills, if empowered and enabled appropriately, can lead the change. Unsurprisingly HR policies and rewards systems are a common theme in the literature. There are clear indications that system shifts, retraining programmes and the generation of top-to-bottom enthusiasm around change are key factors for the success of change programmes. (Waterman, et al., 1980) Similarly, answering frontline employee key questions ("What's in it for me?") can be a key enabler of success when developing sustainable, successful e-learning programmes. Competitive rewards and career progression opportunities are just the start of such initiatives. Teleology, presented with a clear vision and backed by a sequence of realistic goals is currently far from what can be achieved on the ground. Recommendations for an action plan in this regard include capturing the voice of the customer, both internally and externally.

While the localised mission of colleges and their engineering departments is clear, its vision is lacking. Mission, values and goals are well-shaped but lack a clear road map for constant change. Although this could be acceptable practice given the variety of methods used (Johnson, et al., 2012) many staff keep asking for the wider vision. If we focus on how the individuals within an organisation change, the framework identified by Balogun provides a fundamental pillar of making the change a success. In particular "letting go of the past" (Balogun, et al., 2016) and visualising the future. This is a core issue here, reflected by continual questions from staff as to where the institution is going. A feeling of detachment and a lack of opportunities is at the heart of the problem. This poses a challenge to managers and executives alike, particularly when the individuals in question lack, from management point of view, the required credentials for the required change as presented in formal or informal qualifications and experience. A core issue here is whether an educational institution can ignore the importance of qualifications. Furthermore, to train front-line staff requires considerable financial and time investments which are not readily available.

Adopting the change and moving the organisation forward to a sustainable state is easier to achieve when the workforce is ready. (Balogun, et al., 2016) Implementing Kotter's stages will require a focus on and investment in individuals, and when this is magnified to include a whole department or the organisation, the cost, may be unbearable when faced with resistance. (Ford, et al., 2008) A different approach is to revamp the department with new recruits, aiming to empower them to counter the resistance and move forward and to widen the range of external ideas. To overcome the middle manager dilemma (Johnson, et al., 2017), from an executive perspective, a variety of approaches should be considered. While it is disappointing to lead with slow results, the bridging aspect is highly important, particularly when dealing with two groups who lack in-depth understanding of the other group's problems and challenges. Resistance can be a structured mechanism posed by the change agents to fulfil predetermined beliefs. (Ford \& Ford, 2009) The case of middle managers as change agents or implementers is 
different. Lack of power to complete organisation-wide changes and having to deal with problems perceived as "real" only by resistant staff highlights some limitation of the proposed approaches to carry out successful change strategies.

Political skills will be necessary for short-term gains, but social astuteness, interpersonal influence, networking and sincerity will be short-lived with no continuous development. (Buchanan, 2005) To sustain change, leadership requires an-in depth introspection of one's attitude and ability of change. Key skill is the ability develop and draw development plans for oneself and the organisation. With a good e-learning initiative, the institution saves much needed time and resources, but this is not enough to sustain change. (Palmer, et al., 2017) As in academia, technology and other fields, the speed of development should be matched with constant development reflected by new key players, empowering them to act. It is clear from the politics of change that the voice of resistance is powerful and must be heard and considered in any change process. Yet, it is overlooked by senior management leading the change. The ways in which those with the power (Ferris, et al., 2007) to listen consider resistant opinions should move beyond simple forums designed to provide opportunities for front-end staff to be heard to clear problem-solving engagements, and focus on realistic action plans that maintain current business practices for as long as needed. HR-led award mechanisms to boost good initiatives should be in place. Keeping the change momentum has to happen through sustained communication to create new cultures. (Higgins, 2004)

\section{Conclusion}

If a fundamental change is sought, one must revaluate current practice and stand ready to eliminate unsuccessful parts of the business even if this conflicts with the need for constant growth. (Beech \& Macintosh, 2012) In the context of e-learning, true change can come through limiting the offer to a bespoke, well-focused offer for areas with serious potential to sustain successful new approaches. As non-profit organisations, many colleges have an obligation to a plethora of stakeholders. If they change the non-profit model, organisational size will allow to test new strategies (Beer \& Eisenstat, 2000) and successful departments will no longer "carry" failing departments financially. Balancing the different options now seems the best strategy. From an outsider's point of view, this could seem ineffective, but it can be a gamble with winning chances, weighted and changed continually based on flexible management style and consistent adaptation of decision-making.

The pandemic has highlighted many positives of adaptive decision-making. (Martin \& Barber, 2006) On the global stage women leaders are managing crises in this way and heading for unprecedented transformation. Among the reasons for transformation (Kotter, 1996), forming a powerful guiding coalition and empowering others to act on vision remain the main challenging factors to ensure success. On a local just as on a global scale, power shifts should occur to include all main actors of change. Participatory involvement cannot be reflected in one-way communication or hierarchy orders when a deeper understanding, involvement and reward systems should be high on the agenda. They will lead to institutionalizing new approaches, consolidating improvements and producing more change.

All recommendations seem to lead the various change framework initiatives back to a key question which holds true in most change initiatives. "How do we implement changes with scanty resources whilst running a business with over-stretched or under developed workforce, particularly where awarding mechanisms are held by a small group in an ivory tower?" (DiMaggio \& Powell, 1983) Strong and determined governance would possibly want to frame this in a logic of servant leadership. (Ibrahim, 2014) Possible future research directions from these recommendations may lead to high precision statistical analyses of e-learning development and the resulting impacts on student experience, satisfaction and destinations. A clear development of research can focus on the implementation of various teaching, learning and assessment strategies from traditional to contemporary online education and training.

Regardless of the approaches adopted to manage change in the current context, any kind of change will have a considerable impact on the future of colleges and their engineering departments. Strategically, any kind of change will be better than no change at all. All analyses demonstrate that there is a need to improve the teams, the systems and stories of a given department. The next steps to take could seek to draft an action plan for incremental change through an integrated approach combining engineering continuous improvement methodologies and wellestablished change management strategies along with a consistent communication both internally and externally. Future research in this direction could seek to analyse specific aspects of one of the models proposed in this study. A very clear point of interest, for example, would be to investigate college discourse and terminology as an aspect of McKinsey's 7S (stories) to investigate how discourse affects self-representation and by extension selfrealisation for these colleges.

\section{References}

Abdalmenem, S. A. M., Abu-Naser, S. S., Al Shobaki, M. J. \& Abu Amuna, Y. M., 2019. Increasing the Efficiency of Palestinian University Performance through the Implementation of E-Learning Strategies, Online: AUG Repository. 
Augier, M. \& Teece, D. J., 2016. Logical Incrementalism, s.1.: The Palgrave Encyclopedia of Strategic Management.

Balogun, J., 2006. Managing change: steering a course between intended strategies and unanticipated outcomes. Long Range Planning, Volume 39, pp. 29-49.

Balogun, J., Hope Hailey, V. \& Gustafsson, S., 2016. Exploring Strategic Change. 4th ed. Harlow: Pearson.

Beech, N. \& Macintosh, R., 2012. Managing Change: Enquiry and Action. 1 ed. Cambridge, UK: Cambridge University Press.

Beer, M. \& Eisenstat, R. A., 2000. The silent killers of strategy implementation and learning. Sloan Management Review, 41(4), pp. 29-40.

Beer, M. \& Nohria, 2000. Cracking the code of change. Harvard Business Review, 78(3), pp. 133-41.

Buchanan, D. e. a., 2005. No going backk: A review of the literature on sustaining organizational change. International Journal of Management Reviews, 7(3), pp. 189-205.

DiMaggio, P. J. \& Powell, W. W., 1983. The Iron Cage Revisited: Institutional Isomorphism and Collective Rationality in Oganizational Fields. American Sociological Review, 48(2), pp. 147-160.

Ferris, G. R. et al., 2007. Political Skill in Organizations. Journal of Management, 33(3), pp. 290-320.

Ford, J. D. \& Ford, L. W., 2009. Decoding Resistance to Change. Harvard Business Review, 87(4), pp. 99-103.

Ford, J. D., Ford, L. W. \& Amelio, A. D., 2008. Resistance to change: the rest of the story. Academy of Management Review, Volume 23, pp. 362-776.

Georgieva, M. \& Abdelazim, A., 2020. Mergers and Acquisitions in Higher Education A Case Study from the UK. European Journal of Business and Management, 12(31).

Harris, L. C. \& Ogbonna, E., 2002. The unintended consequences of culture interventions: a study of unexpected outcomes. British Journal of Management, 13(1), pp. 31-49.

Higgins, J. M. C., 2004. If you want strategic change don't forget your cultural artefacts. Journal of Change Management, 4(1), pp. 63-73.

Hope Hailey, V. \& Balogun, J., 2002. Devising Context Sensitive Approaches to Change: The Example of Glaxo Welcome. Long Range Planning, 35(2), pp. 153-178.

Ibrahim, I. B., 2014. Servant Leadership and Effective Change Management in Schools. International Journal of Scientific and Research Publications, 4(1).

Johnson, G. et al., 2017. Exploring Strategy. 11 ed. London: Pearson.

Johnson, G., Yip, G. \& Hensmans, M., 2012. Achieving Successful Strategic Transformation. MIT Sloan Management Review, 53(3), pp. 25-32.

Kotter, J. P., 1996. Leading Change. 1 ed. s.1.:Harvard Business School Press.

Liekis, K., 2020. Modelling Team-based Learning Strategy Elements for Bachelor Studies in an E-learning Environment. Contemporary Research on Organization Management and Administration, 8(2), pp. 88-106.

Lowder, T., 2009. The Best Leadership Model for Organizational Change Management: Transfermational Versus Servant Leadership. SSRN Electronic Journal, 1(1).

Martin, C. \& Barber, K. S., 2006. Adaptive decision-making frameworks for dynamic multi-agent organizational change. Autonomous Agent Multi-Agent Systems, 13(1), pp. 391-428.

Mintzberg, H. \& Waters, J., 1985. Of strategies, deliberate and emergent. Strategic Management Journal, 6(3), pp. 257-72.

Morard, B., Stancu, I. \& Stancu, A., 2014. E-Learning in Organizations vs. Universities: Competition or Cooperation?. Singapore, 3rd International Conference on Business, Management and Governance.

NW England Directory, 2020. NW England [Online] Available at: http://www.nw-england.co.uk/education/ [Accessed 28112020$]$.

O'Reilly, C. A. \& Tushman, M. L., 2011. Organizational Ambidexterity in Action: How Managers Explore and Exploit. California Management Review, 53(4), pp. 5-22.

Palmer, I., Dunford, R. \& Buchanan, D., 2017. Managing Organizational Change: A Multiple Perspectives Approach. 3 ed. New York: McGraw Hill Education.

Sharpe, R., Benfield, G. \& Francis, R., 2006. Implementing a university e-learning strategy: levers for change within academic schools. Research in Learning technology, 14(2), pp. 135-151.

Sirkin, H. L., Keenan, P. \& Jackson, A., 2005. The Hard Side of Change Management. Harvard Business Review, Issue October, pp. 109-118.

Tanno, J. P. \& Banner, D. K., 2018. Servant Leaders as Change Agents. Journal of Social Change, 10(1), pp. 118.

Tomblin, B., 2019. Digital Transformation in UK Higher Education. [Online] Available at: https://edtechnology.co.uk/latest-news/live-panel-discussion-digital-transformation-in-ukhigher-education/

[Accessed 2811 2020]. 
Tomic, S., Roberts, E. \& Lund, J., 2020. Designing learning and teaching online: the role of discussion forums. [Online]

Available at: https://www.advance-he.ac.uk/news-and-views/designing-learning-and-teaching-online-rolediscussion-forums [Accessed 2811 2020].

Tsoukas, H. \& Chia, R., 2002. On organizational becoming: rethinking organizational change. Organization Science, 13(5), pp. 567-82.

Van de Ven, A. H. \& Poole, M. S., 1995. Explaining Development and Change in Organizations. Academy of Management Review, 20(3), pp. 510-540.

Waterman, R. H., Peters, T. J. \& Phillips, J. R., 1980. Structure is not organization. Business Horizons, 23(3), pp. 14-26.

White, K. R. J., 2008. Agile Project Management: A Mandate for the Changing Business Environment. Denver, USA, The Project Management Institute. 